MagNetE workshop 2011

\title{
Influence of solar activity on magnetic network measurements
}

\author{
Roberta Tozzi ${ }^{\star}$, Guido Dominici, Paola De Michelis, Antonio Meloni
}

Istituto Nazionale di Geofisica e Vulcanologia, Roma, Italy

Article history

Received October 21, 2011; accepted February 28, 2012.

Subject classification:

Magnetic repeat stations, Solar activity, Magnetic models.

\begin{abstract}
The influence of solar activity on magnetic measurements taken during the Italian repeat station surveys performed in 1999/2000 and 2009/2010 has been investigated. A method to estimate the difference between the 2000.0 and 2010.0 surveys in terms of the "residual" (i.e. not completely reduced) external contribution is proposed. This method is also based on the removal of the contribution due to the magnetic field of internal origin by means of CHAOS3 model from magnetic repeat station measurements. The origin of the observed differences is interpreted in terms of the very different level of solar activity between 2000.0 and 2010.0. Indeed, results seem to suggest that differences could be attributed to the enhanced ring current intensity during a phase of solar maximum. The investigation of the spatial patterns of these differences suggests that they could be reduced by introducing a larger number of variometer stations, especially during surveys performed under conditions of high solar activity.
\end{abstract}

\section{Introduction}

As many other countries worldwide, Italy has a long standing tradition in magnetic repeat station surveys, and since 1979 measurements have been repeated regularly every five years at about a hundred points distributed quite uniformly on the Italian territory [Molina et al. 1985, Meloni et al. 1988, Meloni et al. 1994, Coticchia et al. 2001, Dominici et al. 2007, Dominici et al. 2012]. These measurements allow the compilation of magnetic charts that are generally used for navigational purposes, and also representing and modeling the geomagnetic field and its secular variation on the regional scale [De Santis et al. 2003] with a detail that would not be achievable only using data from the two Italian magnetic observatories of L'Aquila (AQU) and Castello Tesino (CTS). Moreover, the collection of magnetic repeat station data from many countries makes it possible to model, for instance, time-varying magnetic anomalies over broad regions as proposed by Korte and Haak [2000] for the case of Europe.

When measuring the magnetic field at the Earth's surface, the instruments record the superposition, at the time of the measurement, of the magnetic fields produced by different sources. These sources, which differ in nature and location, also widely differ in magnitude and spatio-temporal behavior. It is known that a magnetic measurement on the ground includes essentially two magnetic fields: one of internal origin and the other of external origin.

The magnetic field of internal origin is the sum of the main and crustal fields. The main field, which is produced within the core through a self-sustaining dynamo process, is the most intense and changes on secular timescales. The crustal field is weaker, on average, and it is mainly due to induced magnetization in the crust by the main magnetic field. Induced magnetization results in magnetic anomalies, which to our purposes can be considered practically constant in time, as shown by Thébault et al. [2009].

As already stated, the Earth's magnetic field arises also from sources outside the Earth. These external fields, which result from the interplay between the magnetic field of the Earth and that of the Sun, are mainly produced by the electric currents flowing in the ionosphere and magnetosphere. These are highly variable: some changing on the timescale of seconds, others on the timescale of days or longer. At ground observatories the typical amplitudes of the disturbance resulting from external fields range between a few and some hundred nT. Furthermore, the interaction between temporal fluctuations of the Earth's external magnetic field and electrically conductive rocks of the Earth generates internal (crust and upper mantle) secondary electric and magnetic fields. The resulting magnetic fields are the so-called electromagnetically induced fields.

Unfortunately, magnetometers can measure only the field resulting from the superposition of the different contributions, so if we are interested in obtaining an accurate estimation of secular variation using data coming from magnetic repeat station surveys, it is consequently important to remove all external fields from data.

To obtain repeat station data the least affected by external fields, a number of recommendations should be followed, both in the execution of measurements and also in their postprocessing [Newitt et al. 1996]. However, for a series of practical reasons not all of these recommendations can be strictly followed and this unavoidably leads to data that could partly include the external fields; this contribution could be related, 
for instance, to the level of solar activity. Indeed, the external fields can strongly be affected by the solar wind, a stream of electrically charged particles that is constantly emitted by the Sun. Under certain conditions of interplanetary magnetic field, the enhanced emission of radiation and charged particles associated with solar phenomena, such as for instance coronal mass ejections and solar flares, increases the ionospheric and magnetospheric currents giving rise to rapidly varying magnetic fields. Thus, the contribution of the external magnetic fields to the measured magnetic field is modulated by the eleven-year solar activity cycle.

The purpose of this paper is to investigate if measurements of the Italian magnetic repeat station surveys can be affected by additional external fields due to enhanced solar activity. The paper is organized as follows: in Section 2 we briefly describe the data used and our method of analysis then, in Section 3 we illustrate the application of this method to the Italian magnetic network data together with a discussion of results.

\section{Method and data}

As already mentioned, magnetic repeat station data are meant to represent the field of internal origin (main and crustal fields) and, for this reason, all transient external variations must be removed. We emphasize that the external magnetic fields may give a significant contribution to the measured magnetic field even at mid latitudes where the Italian magnetic network is located. Indeed, although at mid latitudes we are far away from the equatorial as well as the polar electrojects, the occurrence of geomagnetic storms can considerably influence the terrestrial magnetic field. The characteristic signature of a geomagnetic storm is a depression in the horizontal intensity $H$ of the magnetic field lasting normally several hours to a few days. This depression is caused by the growth of the ring current flowing westward in the magnetosphere, and can be monitored by the Dst index. It is generally accepted that storms are temporary disturbances of the geomagnetic field during which Dst is less than $-50 \mathrm{nT}$. According to this criterion, 20-50 storm events occur annually, depending on solar activity. Indeed, the number and intensity of storms vary with the eleven-year solar activity cycle with about one-year lag. The dependence of the total external field intensity on solar activity level can be observed in Figure 1 that shows maps of the difference of the total external component of the magnetic field (magnetospheric and ionospheric, both primary and induced) for $X$, $Y$ and $Z$ Cartesian components between the epochs 1995.0 and 2000.0 (i.e. close to a period of minimum and maximum, respectively). The values of $X, Y$ and $Z$ at 1995.0 and 2000.0 used to estimate these differences have been obtained by means of the comprehensive model CM4 [Sabaka et al. 2004] that separately models all sources of the Earth's magnetic field. From Figure 1 we observe that the component most affected by the enhanced solar activity is the North component $(X)$ and that this influence is characterized by a marked latitudinal dependence. This result can be understood taking into account that, as already mentioned, a significant contribution to the magnetic field of external origin is given by the ring current which causes a magnetic field perturbation that at the equator is parallel to the terrestrial dipole magnetic field but directed southward. Actually, if ionospheric and magnetospheric contributions were mapped separately, the magnetospheric part would result to be one order of magnitude greater than the ionospheric part. So, what Figure 1 exhibits practically coincides with the magnetospheric contribution.

A way to remove all transient external variations from
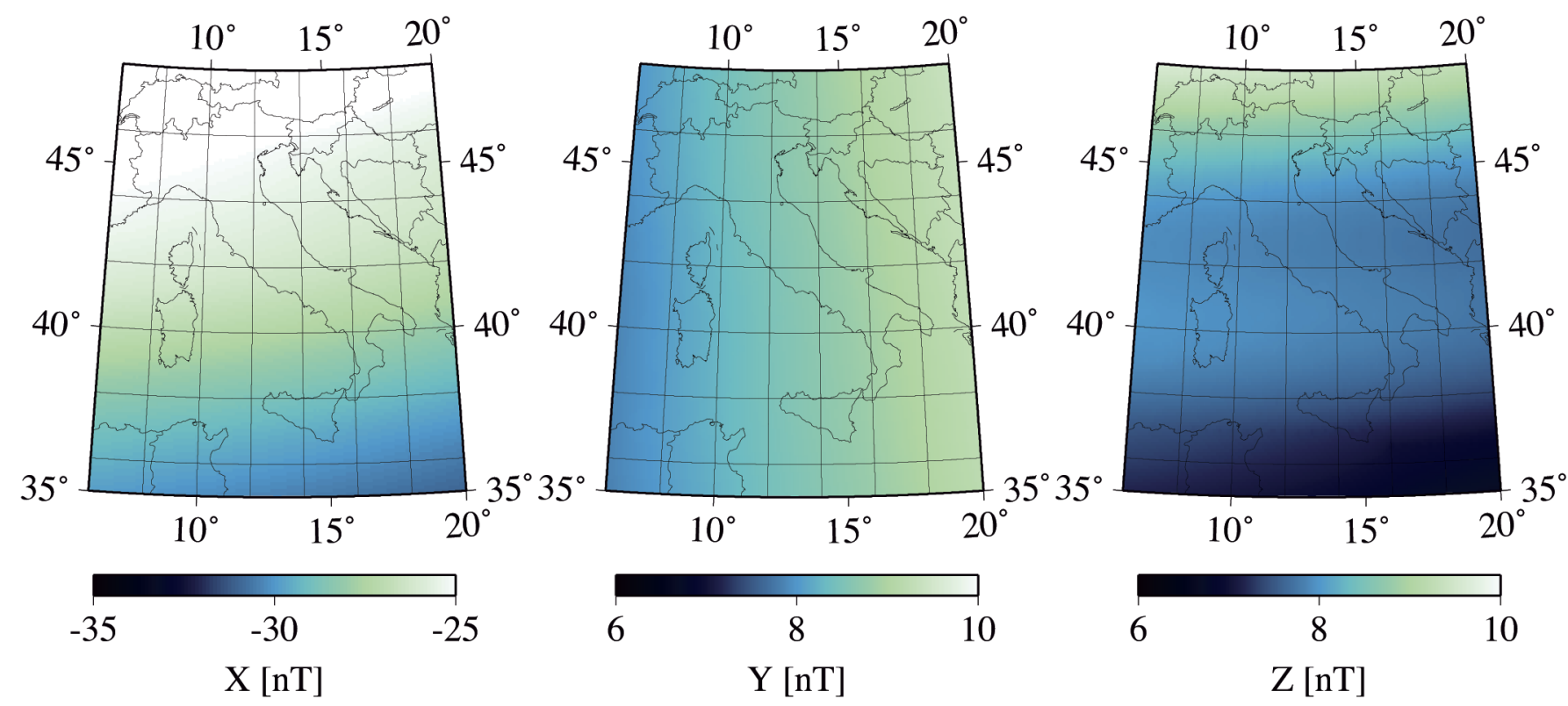

Figure 1. Difference in the total external contribution, i.e. magnetospheric and ionospheric primary and induced, between 2000.0 (maximum solar activity) and 1995.0 (minimum solar activity) estimated by means of CM4 model for $X, Y$ and $Z$ magnetic components. 


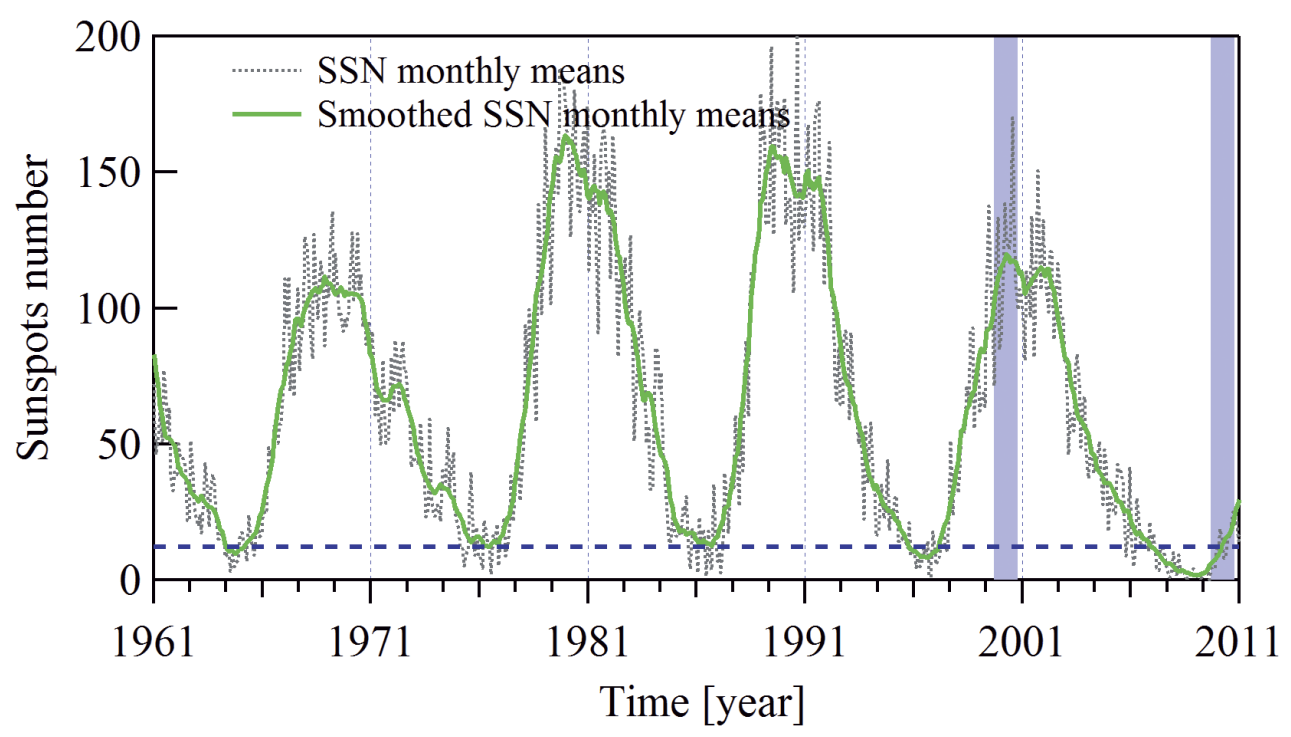

Figure 2. Values of sunspots number (SSN) between 1961.0 and 2011.0. Lilac areas indicate the time intervals during which magnetic surveys of 2000.0 and 2010.0 have been undertaken, the blue horizontal dashed line indicate the average number of sunspots observed between September 2009 and October 2010.

magnetic repeat stations data is to follow the recommendations suggested by Newitt et al. [1996]. These include the proper choice of a site where to install the repeat and variometer stations. For what concerns repeat stations, Newitt et al. [1996] describe the proper execution of absolute measurements (for instance, during a time with low daily variation and during magnetically quiet days) and also the proper data reduction using records from the magnetic observatories and installed local variometers.

We underline that data used in this study have been collected on points of the Italian magnetic network following the main indications suggested by Newitt et al. [1996]. In particular, two magnetic observatories and four variometers have been used for data reduction (for the location of variometers and observatories, refer to Figure 4). Indeed, when a repeat station is far from a magnetic observatory, local variometers data are used to establish the real instantaneous variation of the magnetic field.

We will focus on the survey of 2000.0 that was performed, as shown in Figure 2, during a phase of maximum activity of the last solar cycle. We recall here that to quantify solar activity the so-called relative sunspot number, also known as the Wolf sunspot number, is generally used. In order to quantify the additional external fields, we need to compare data taken during the 2000.0 survey (the survey was performed between September 1999 and October 2000) to repeat station data relative to a period of minimum activity in order to fix a sort of "ground state" for magnetic repeat station data. Taking advantage of the peculiar features of solar cycle 23 , that was exceptionally long and characterized by a very marked minimum that was reached in December 2008, we chose the 2010.0 survey as term of comparison. This survey was performed between September 2009 and October 2010 and, even if it fell during the ascending phase of solar cycle 24 , the average number of sunspots during this time in- terval is comparable to the number of sunspots at minima of previous solar cycles. In fact, even though solar cycle 23 reached its minimum in December 2008, solar activity remained very quiet throughout 2009 and also in 2010 the sunspot activity has been extraordinarily low [Pulkkinen et al. 2011]. It's worth underlining that, despite the availability of data from other previous surveys, we preferred to focus on data from the most recent ones, since they are characterized by a higher accuracy, and we believe they could allow more accurate estimation of the additional external contribution.

The two surveys consist of measurements of declination $D$, inclination $I$ and total field $F$ at 113 and 129 points, respectively. $D, I$ and $F$ have been converted to $X, Y$ and $Z$ components to better interpret results. Considering data only from points reoccupied in both surveys, the final size of the magnetic network here considered is of 108 stations, that are quite uniformly distributed on the Italian territory with a mean distance of about $60 \mathrm{~km}$. This value of repeat stations spacing guarantees that phenomena such as piezomagnetic effects typical of tectonically active areas characterized by high magnetic anomalies, as much of the Italian territory is [Caratori Tontini et al. 2004] - and electromagnetic induction effects due to the seas surrounding Italy do not significantly distort the true secular variation [Newitt et al. 1996]. Data used for this study are already reduced for the daily variation recorded at the nearest magnetic observatory or variometer; so they are reduced at $02 \mathrm{UT}$ of the day of measurement.

If measurements have been correctly performed and data properly reduced, theoretically the considered datasets are expected not to contain a significant external contribution (the ionospheric effect having been removed by reduction at observatory/variometer, and magnetospheric effect having been avoided by taking measurements during magnetically quiet days) and to be representative of the main and crustal fields. In order to check for the presence of a residual 
external contribution in these datasets, we first need to remove the internal field by means of a global model as IGRF [Finlay et al. 2010] or CHAOS3 model [Olsen et al. 2010]. Some tests, made to verify which of them could better represent the magnetic field on the Italian territory, have shown that they are practically equivalent and that the choice of the model does not substantially change the results of this study. However, since CHAOS3 model estimates secular variation on Italy slightly better than IGRF, all estimations have been made using CHAOS3. After all, with respect to IGRF, CHAOS3 model is characterized by a higher resolution both in time and space. While IGRF consists of a spherical harmonics expansion up to degree 13 and with a time resolution of five years, CHAOS3 model is characterized by an expansion up to degree 60 and by a time resolution of 6 months, that is the spacing between cubic splines knots [Olsen et al. 2010].

So, we estimated at the location of each of the 108 selected repeat stations, values of $X, Y$ and $Z$ components from CHAOS3 model at epochs 2000.0 and 2010.0. Then, at each point and for each component, CHAOS3 value has been subtracted from the corresponding repeat station data for both 2000.0 and 2010.0 epoch. In practice, at epoch $T$ and for each field component, we could define a residual $R_{T}$ as the difference between the value of the magnetic field measured during the survey at the repeat station (RS) with coordinates $\theta$ and $\phi$ and the value of the magnetic field modeled by CHAOS3 at the point with the same coordinates as:

$$
R_{T}(\theta, \phi)=R S_{T}(\theta, \phi)-\operatorname{CHAOS}_{T}(\theta, \phi)
$$

We expect that maps of the residuals $R_{T}(\theta, \phi)$ obtained for a given epoch represent the sum of the crustal field that is not modeled by CHAOS3 and the part of the external contribution that it has not been possible to reduce. Let now consider, for each value of $\theta$ and $\phi$, the difference $\Delta R(\theta, \phi)$ defined as follows:

$$
\Delta R(\theta, \phi)=R_{2000.0}(\theta, \phi)-R_{2010.0}(\theta, \phi),
$$

assuming that the portion of the crustal field not modeled by CHAOS3 that is still contained in the data does not change in time, we can think of $\Delta R$ as representing the difference between the residual external contribution between 2000.0 and 2010.0. We recall here that the time interval covered by the 2010.0 magnetic survey has been a period of very low solar activity characterized by an average number of sunspots equal to 13 and that this value is comparable to the number of sunspots of other solar minima. On this basis it is reasonable to assume the survey of 2010.0 as practically not influenced by the external contribution. At the light of these considerations, the quantity $\Delta R(\theta, \phi)$ can be interpreted as the additional external contribution, namely the ionospheric and magnetospheric fields (primary and induced), due to conditions of high solar activity, that affected the 2000.0 survey.

\section{Results and conclusions}

Following the procedure described above, the spatial distribution of $\Delta R(\theta, \phi)$ has been estimated for all Cartesian components of the geomagnetic field. Then, values of $\Delta R(\theta, \phi)$ over the 108 selected repeat stations have been interpolated using the method of gridding with continuous curvature splines in tension [Smith and Wessel 1990] to obtain maps shown in Figure 3. The choice of this particular interpolation method is motivated by its ability to eliminate fictitious
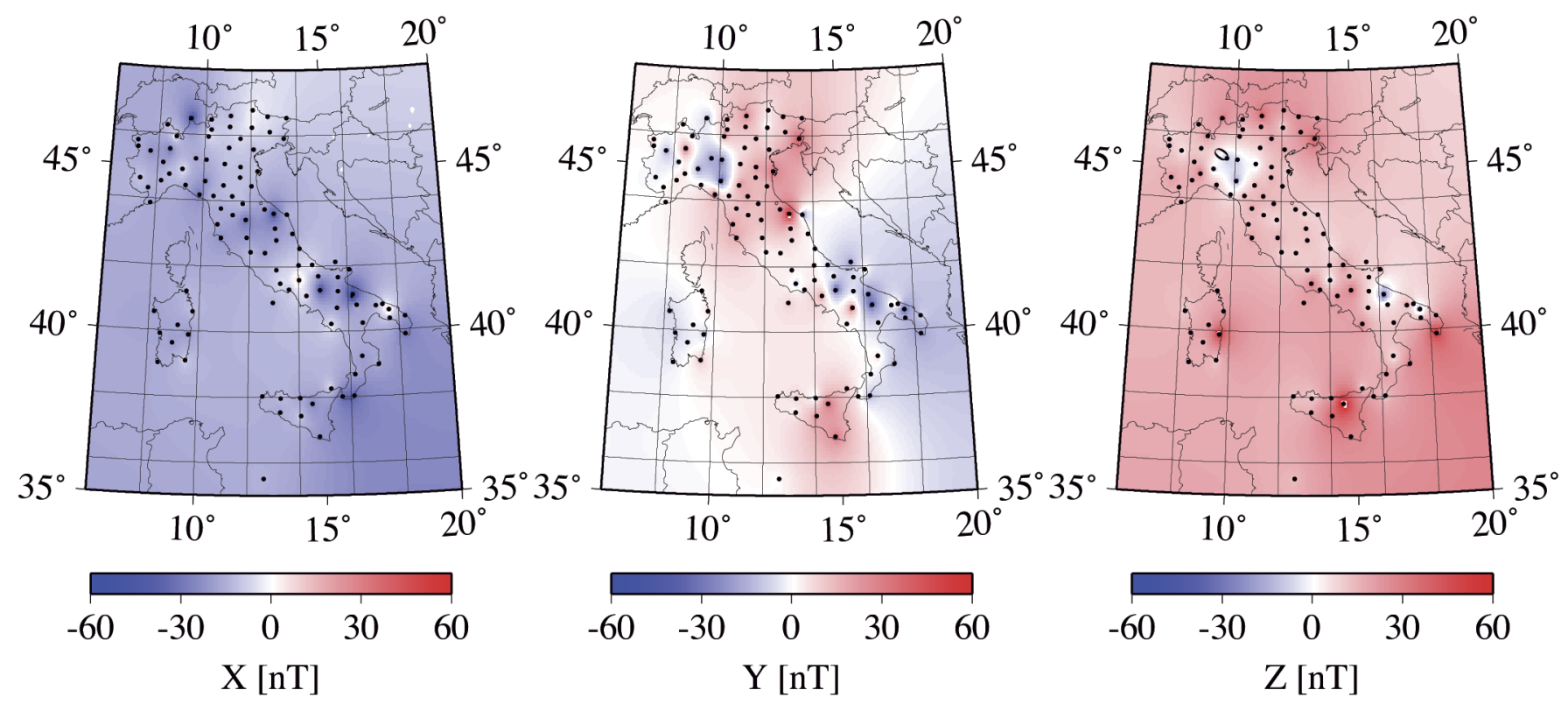

Figure 3. Maps of $\Delta R$ for $X, Y$ and $Z$ components. The average value, estimated over all stations, of $\Delta R$ is of about $-16 \mathrm{nT}, 2 \mathrm{nT}$ and $16 \mathrm{nT}$ for $X, Y$ and $Z$, respectively. Black dots indicate the position of magnetic repeat stations. 

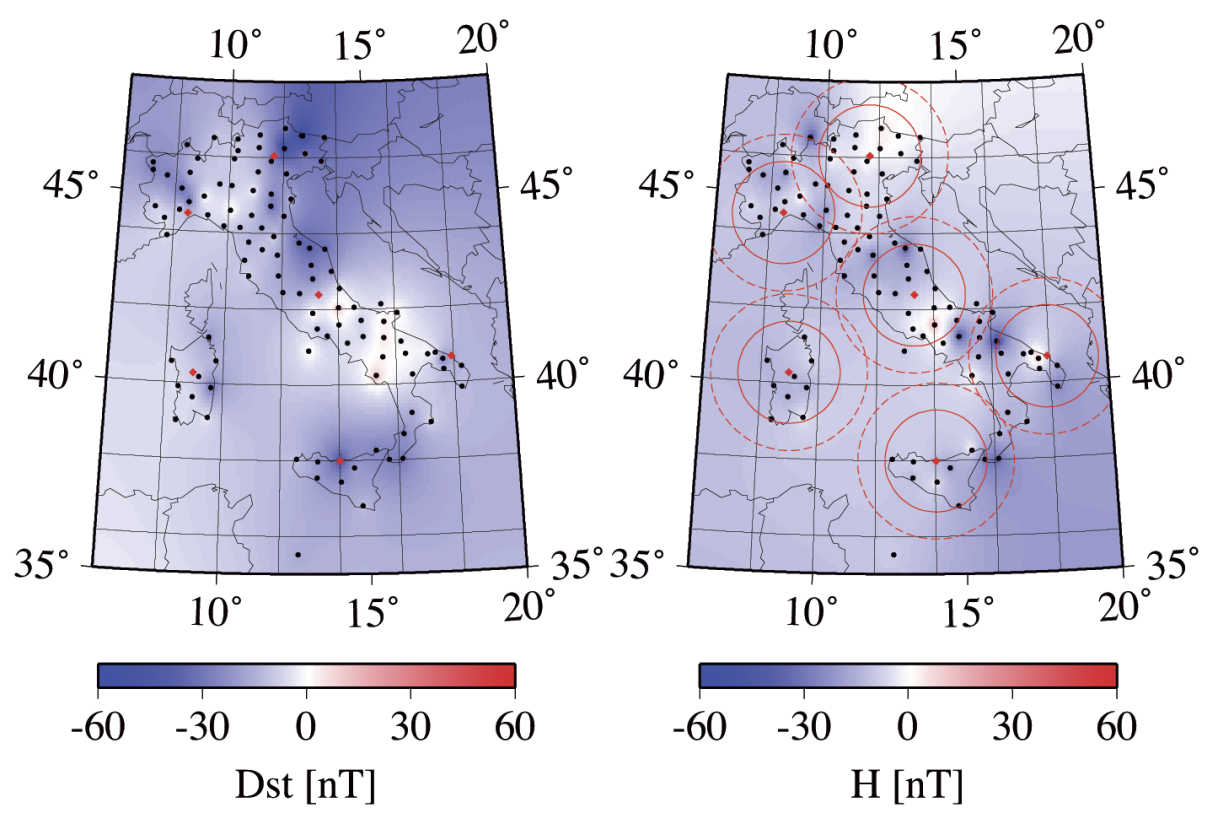

Figure 4. On the left a map of the difference of daily Dst index at the times of 2000.0 and 2010.0 surveys, on the right the map of $\Delta R$ for the horizontal component $H$. Black dots indicate the position of magnetic repeat stations, red dots indicate the position of magnetic observatories and variometers Dashed circles have a radius of $230 \mathrm{~km}$, while solid circles have a radius of $150 \mathrm{~km}$.

inflection points typical of other methods as that of minimum curvature.

From Figure 3 we observe that the algebraic sign of the residual $\Delta R$ relative to the $X$ component well agrees with the direction of the magnetic field associated to the flow of the ring current. Actually, a decrease of the horizontal component $H$ corresponds to an enhancement of the ring current intensity. Due to the geometry of the ring current and to the features of the present main field, over the area under investigation, this effect is suffered mainly from the $X$ component as also shown by Figure 1. According to Figure 3, the residual $\Delta R$ relative to the $X$ component takes only negative values whose average over all repeat stations gives $-16 \mathrm{nT}$. This average is of the same order of magnitude of the analogous mean value found by means of CM4 $(-25 \mathrm{nT})$ but its lower value could be related to the effect of data reduction applied on magnetic measurements, but also to differences inherent to the two datasets. The average found using CM4 has been estimated from 1995.0 and 2000.0 annual means, while the average of the residual $\Delta R$ relative to the $X$ component has been estimated using data for the days of observation and for 2000.0 and 2010.0 epochs. Of course it is not possible to distinguish between the primary and induced residual external contribution. The residual relative to the $Y$ component is characterized by a very low value of the average over all repeat stations (of about $2 \mathrm{nT}$ ). This is not surprising since, as already mentioned, magnetospheric currents are, in general, responsible of a magnetic field in the direction of the $H$ component that, over Italy, practically coincides with the direction of the $X$ component. Differently, the distribution of residuals relative to the $Z$ component is a bit more complex in space and could be interpreted in terms of the presence of discontinuities in the electrical conductivity of the crust and upper mantle that are responsible for electromagnetically induced magnetic fields.

At this point, it would be interesting to understand how to improve the procedure used to remove the external contribution from magnetic repeat station data in order to more and more increase the accuracy of next magnetic repeat surveys, especially those performed under conditions of high solar activity. A first step is to understand if the highest values of the residual $\Delta R$ observed in the $X$ component are closely related to the intensity of the ring current at the time of the measure. To answer this question we drawn a map of differences of the daily Dst index (left side of Figure 4), where the Dst index is a measure of the strength of the equatorial ring current. In practice, at each repeat station it has been associated the difference between the daily Dst index of the day when that repeat station was occupied during the 2000.0 survey and the Dst index of the day when the same repeat station was occupied during the 2010.0 survey. So, left side of Figure 4 represents the different conditions of ring current intensity under which magnetic repeat stations have been reoccupied in the considered surveys. Since Dst is estimated from the horizontal component $H$, on the right side of Figure 4 we reported a map, analogous to those reported in Figure 3, but this time relative to the $H$ component.

From Figure 4 we notice that there are regions very little affected by the residual external field despite measurements of the 2000.0 survey have been taken under conditions of magnetic activity worse than those of the 2010.0 survey (high values of the difference of Dst). One of these regions is, for instance, the north-eastern part of Italy, near the observatory of Castello Tesino $\left(11.65^{\circ} \mathrm{E}, 46.05^{\circ} \mathrm{N}\right)$. Also the areas nearby the 
observatory of L'Aquila $\left(13.317^{\circ} \mathrm{E}, 42.383^{\circ} \mathrm{N}\right)$ and the variometer of Brindisi $\left(17.922^{\circ} \mathrm{E}, 40.673^{\circ} \mathrm{N}\right)$ are characterized by a low value of the residual external field, despite measurement in 2000.0 have been made under less favorable conditions of solar activity with respect to those made in 2010.0.

The only area where this discussion does not hold is that between $14^{\circ} \mathrm{E}$ and $17^{\circ} \mathrm{E}$ of longitude and $40^{\circ} \mathrm{N}$ and $42^{\circ} \mathrm{N}$ of latitude. Measurements in this region have been made in 2000.0 and 2010.0 under similar conditions of ring current intensity as revealed by the very low value, in the same area, of the Dst differences. Nonetheless, measurements of 2000.0 survey seem to contain a much higher residual external contribution than 2010.0 survey. This could be interpreted in terms of the origin of the external contribution. In fact, by selecting Dst index we are evaluating external contributions related mainly to the ring current and in minor part also to other large scale currents (ionospheric, fieldaligned and tail currents) [Campbell 1996]. However, since Dst is evaluated from magnetic observatories close to the magnetic equator, it might not represent the whole external contribution at the latitudes of the Italian magnetic network. So, the anomalous external contribution measured between $14^{\circ} \mathrm{E}$ and $17^{\circ} \mathrm{E}$ of longitude and $40^{\circ} \mathrm{N}$ and $42^{\circ} \mathrm{N}$ of latitude during the 2010.0 survey could be related to phenomena, either ionospheric or magnetospheric, whose effects are not included in the Dst index.

A completely different interpretation could be given in terms of long-term magnetic effects that can be observed near active faults and volcanoes [Johnston 1989]. Actually, from the analysis of a large GPS dataset, it seems that the surface of the area we are referring to, undergoes a complex deformation pattern, due to the fact that it is crossed by the Adriatic-Ionian thrust, also related to a possible upwelling of mantle flow [Devoti et al. 2011].

In any case, by a more careful inspection of Figure 4 we observe that the regions characterized by the highest residual external contribution are those in the proximity of the boundary of the red dashed circles. These circles are centered on the magnetic observatory/variometer used for data reduction and have a radius of $230 \mathrm{~km}$. Regions nearby magnetic observatories and variometers are almost all characterized by low external residual contribution. This evidences the importance of choosing the distance between a repeat station and a variometer so as to guarantee the validity of the assumption that the magnetic variation at the repeat station and at the variometer can be assumed to be the same. This means that especially under magnetically perturbed conditions, that are frequent during a period of high solar activity, the use of a larger number of variometers would be preferable. The maximum distance between the repeat stations and the variometer should be no more than $100-150 \mathrm{~km}$. Indeed, the areas inside the small red solid circles, whose radius is $150 \mathrm{~km}$, are all characterized by low external residual. Actu- ally, Newitt et al. [1996] do suggest that the variometer should be located within a few hundred meters from the repeat station, however this is not always feasible, so it is common to accept distances of more than a hundred kilometers between a repeat station and a variometer. The value of 100$150 \mathrm{~km}$ for the maximum distance between repeat stations and the variometer is, of course, only a rough indication. In fact, it is difficult to specify a unique value for the validity distance, since the features of electromagnetically induced magnetic fields strongly depends on the internal electrical conductivity structure. Large values of this distance can be confidently used wherever the electrical conductivity of the crust is sufficiently homogeneous. For instance, this is not the case of the northern Apennines, in particular the area approximately between $11^{\circ} \mathrm{E}$ and $14^{\circ} \mathrm{E}$ of longitude and $42^{\circ} \mathrm{N}$ and $43^{\circ} \mathrm{N}$ of latitude. Here Armadillo et al. [2001] found, at the transition between the Tyrrhenian and the Adriatic domains, the existence of a sudden discontinuity in the deep conductive layer that underlies the Apennine chain at about $20 \mathrm{~km}$ depth.

In any case, an interesting attempt to reduce repeat station measurements to quiet night time levels without installing variometers, as could be the case of remote areas, has been described by Matzka et al. [2009]. In this case, data reduction has been performed using CM4 model to reconstruct the ionospheric and magnetospheric contribution.

Acknowledgements. The Authors are grateful to all the people of the Istituto Nazionale di Geofisica e Vulcanologia that have been involved in the magnetic surveys investigated in this study, and to two anonymous referees for their useful suggestions. Figures 1, 3 and 4 were drawn using the Generic Mapping Tools [Wessel and Smith 1998].

\section{References}

Armadillo, A., E. Bozzo, V. Cerv, A. De Santis, D. Di Mauro, M. Gambetta, A. Meloni, J. Pek and F. Speranza (2001). Geomagnetic depth sounding in the Northern Apennines (Italy), Earth Planets Space, 53, 385-396.

Campbell, W.H., (1996). Geomagnetic storms, the Dst ringcurrent myth, and lognormal distribution, J. Atmos. Terr. Phys, 58, 1171-1187.

Caratori Tontini, F., P. Stefanelli, I. Giori, O. Faggioni and C. Carmisciano (2004). The revised aeromagnetic anomaly map of Italy, Annals of Geophysics, 47 (5), 1547-1555.

Coticchia, A., A. De Santis, A. Di Ponzio, G. Dominici, A. Meloni, M. Pierozzi and M. Sperti (2001). Italian magnetic network and geomagnetic field maps of Italy at 2000.0, Bollettino di Geodesia e Scienze Affini, 60, 261-291.

De Santis, A., L.R. Gaya-Piqué, G. Dominici, A. Meloni, J.M. Torta and R. Tozzi (2003). ITalian Geomagnetic Reference Field ITGRF: update for 2000 and secular variation model up to 2005 by autoregressive forecasting, Annals of Geophysics, 46 (3), 491-500.

Devoti, R., A. Esposito, G. Pietrantonio, A.R. Pisani and F. 
Riguzzi (2011). Evidence of large scale deformations patterns from GPS data in the Italian subduction boundary, Earth Planet. Sci. Lett., 311, 230-241.

Dominici, G., A. Meloni, M. Miconi, M. Pierozzi and M. Sperti (2007). Italian Magnetic Network and Geomagnetic Field Maps of Italy at year 2005.0, Bollettino di Geodesia e Scienze Affini, 66, 25-47.

Dominici, G., A. Meloni, A. Di Ponzio and M. Miconi (2012). Italian magnetic network and magnetic reference fields at 2010.0, Annals of Geophysics, 55 (6); doi:10.4401/ag5411.

Finlay, C.C., S. Maus, C.D. Beggan, T.N. Bondar, A. Chambodut, A. Chulliat, V.P. Golovkov, B. Hamilton, M. Hamoudi, R. Holme, G. Hulot, W. Kuang, B. Langlais, V. Lesur, F.J. Lowes, H. Luhr, S. Macmillan, M. Mandea, S. McLean, C. Manoj, M. Menvielle, I. Michaelis, N. Olsen, J. Rauberg, M. Rother, T.J. Sabaka, A. Tangborn, L. Toffner-Clausen, E. Thebault, A.W.P. Thomson, I. Wardinski, Z. Wei and T.I Zvereva (2010). International Geomagnetic Reference Field: The Eleventh Generation, Geophys. J. Int., 183, 1216-1230.

Johnston, M.J.S. (1989). Review of magnetic and electric field effects near active faults and volcanoes in th U.S.A., Phys.Earth Planet. Int., 57, 47-63.

Korte, M., and V. Haak (2000). Modelling European magnetic repeat station and survey data by SCHA in search of timevarying anomalies, Phys. Earth Planet. Int., 122, 205-220.

Matzka, J., N. Olsen, C. Fox Maule, L.W. Pedersen, A.M. Berarducci and S. Macmillan (2009). Geomagnetic observations on Tristan da Cunha, South Atlantic Ocean, Annals of Geophysics, 52 (1), 97-105.

Meloni, A., O. Battelli, A. G. Dominici, S. Arca and A. Marchetta (1988). Italian magnetic network at 1985.0, Bollettino di Geodesia e Scienze Affini, 4, 339-350.

Meloni, A., O. Battelli, A. De Santis and G. Dominici (1994). The 1990.0 magnetic repeat station survey and normal reference fields for Italy, Annali di Geofisica, 37 (5), 949-967.

Molina, F., E. Armando, R. Balia, O. Battelli, E. Bozzo, G. Budetta, G. Caneva, M. Ciminale, N. De Florentiis, A. De Santis, G. Dominici, M. Donnaloia, A. Elena, V. Iliceto, R. Lanza, M. Loddo, A. Meloni, E. Pinna, G. Santarato and R. Zambrano (1985). Geomagnetic survey of Italy. Repeat stations network and magnetic maps: a short report, Annales Geophysicae, 3, 365-368.

Newitt, L.R., C.E. Barton and J. Bitterly (1996). Guide for Magnetic Repeat Station Surveys. International Association of Geomagnetism and Aeronomy, Boulder USA.

Olsen, N., M. Mandea, T.J. Sabaka and L. Tøffner-Clausen (2010). The CHAOS-3 geomagnetic field model and candidates for the $11^{\text {th }}$ generation IGRF, Earth Planets Space, 62, 719-727.

Pulkkinen, T.I., E.I. Tanskanen, A. Viljanen, N. Partamies and K. Kauristie (2011). Auroral electrojets during deep solar minimum at the end of solar cycle 23, J. Geophys. Res., 116, A04207.

Sabaka, T.J., N. Olsen and M. Purucker (2004). Extending comprehensive models of the Earth's magnetic field with Oersted and CHAMP data, Geophys. J. Int. 159, 521-547.

Smith, W.H.F, and P. Wessel (1990). Gridding with continuous curvature splines in tension, Geophysics, 55, 293-305.

Thébault, E., K. Hemant, G. Hulot and N. Olsen (2009). On the geographical distribution of induced time-varying crustal magnetic fields, Geophys. Res. Lett., 36, L01307; doi:10.1029/2008GL036416.

Wessel, P., and W.H.F. Smith (1998). New, improved version of Generic Mapping Tools released, EOS Trans. Amer. Geophys. U., 79, 579.

\footnotetext{
${ }^{\star}$ Corresponding author: Roberta Tozzi, Istituto Nazionale di Geofisica e Vulcanologia, Roma, Italy; email: roberta.tozzi@ingv.it.
}

C 2012 by the Istituto Nazionale di Geofisica e Vulcanologia. All rights reserved. 